\title{
Reduction of emissions and fuel consumption in a compression ignition engine using nanoparticles
}

\author{
H. Soukht Saraee $\cdot$ S. Jafarmadar $\cdot$ \\ H. Taghavifar $\cdot$ S. J. Ashrafi
}

Received: 12 February 2014/Revised: 6 January 2015/Accepted: 12 January 2015/Published online: 3 February 2015

(C) Islamic Azad University (IAU) 2015

\begin{abstract}
In this paper, the effect of adding nanoparticles on the performance characteristics of diesel engine was investigated. Up to now, several metallic nanoadditives including cerium and aluminum have been applied in this area. However, the possibility of using some other metals or modification in the additive structures as well as improving or changing the basic fluid is among factors manifesting a broad scope of work in this area. For this purpose, the silver nanoparticles were used as additives to the net diesel fuel. The results are indicative of significant alteration in the engine power, oil temperature, and the proportion of the released pollutants. The presence of the metallic nanoparticles inside the combustion chamber augments the heat transfer to fuel and shortens the ignition delay through an acceleration of the burning process. Meanwhile, these particles can aid fuel particles further penetrate in the compressed air during the spraying stage. Having all of these features altogether will improve combustion and hence the unburned carbons and other pollutants will decrease. Based on these observations, the rate of $\mathrm{CO}$ and NOx would be reduced significantly up to 20.5 and $13 \%$, respectively, noting that the net diesel and $\mathrm{HC}$ would undergo the highest change (up to $28 \%$ ). The results also indicate a $3 \%$ fuel consumption reduction accompanied with $6 \%$ improvement in the engine power, utilizing nanoparticles in most cases.
\end{abstract}

H. Soukht Saraee $(\varangle) \cdot$ S. Jafarmadar · H. Taghavifar Mechanical Engineering Department, University of Urmia, Urmia, West Azerbaijan 57561-15311, Iran

e-mail: h.mechanic65@gmail.com

S. J. Ashrafi

Iran, Nanotechnology Department, University of Tehran,

Tehran, Iran
Keywords Emissions · Fuel - Diesel · Engine · Nanoparticle $\cdot$ Additive

\section{Introduction}

One of the most important issues raised in the automotive industry is the reduction in the fuel consumption and the pollutants from the combustion in the internal combustion engines. Previous works implemented in this field include changing the engine design, improving the quality of fuel, applying techniques on the exhaust gas and especially employing emulsification, and additives/fuel supplements (Bertola et al. 2003; Harbach and Agosta, 1991; Jung et al. 2005; Satge De Caro et al. 2001; Xiaolu et al. 2006). Additives even at the microscale have limitations and problems dealing with sedimentation, conglomeration, and nonuniform distribution. With the advent of nanotechnology in recent years, the aforementioned problems were largely resolved and considerable conclusions were made that will be dealt with subsequently.

Application of nanoparticles in fuel and the study of combustion process considering nanoparticles effect were initially reported in solid fuels and propulsion engines (Galfetti et al. 2007). According to the research conducted in 1997 by Ivanov and Tepper (1997), aluminum nanoparticles could increase the burning rate of the charge in comparison with microparticles. Furthermore, nanoparticles application in fuel demonstrated shorter ignition delay in combustion process when compared to that of microparticles (Pivkina et al. 2004). Moreover, nanoparticles featuring high surface area to volume ratio lead to more contact area between fuel and oxidizer (De Luca et al. 2005). According to the researches carried out in 2004, addition of aluminum nanopowder to the rocket fuel will 
increase the combustion efficiency (Evans et al. 2004). In another research (Kuo et al. 2004), it was revealed that Boron nanoparticles have high potential in the burning rate of solid propellants due to the existence of high heat content of combustion and more heat release rate. Hence, these nanoparticles can dynamically boost the combustion process through reducing the ignition delay, the burning time, and increasing the momentum density which in its own turn can improve the fuel's injection velocity into the combustion chamber.

In other research (Yetter et al. 2009), the interaction between metallic particles and nanotechnology in combustion phase was investigated. In addition, the combustion behavior of some metals was studied, wherein the combustion regimes of the metal particles were analyzed. This research also covers the combustion behavior of the aluminum nanoparticles. According to their work, the application of nanoparticles in the combustion systems is classified into five cases, namely: nanofluids, gels, solid propellants, solid fuels, and thermites.

In recent years, the application of nanoparticles in the combustion systems including liquid and hydrocarbon fuels drew the attention of the researchers. It was demonstrated (Tyagi et al. 2008) that the possibility of the ignition of diesel fuel with aluminum nanoparticles is much higher than the pure diesel fuel. Based on the performed tests (Gan and Qiao 2011) on the micro/nanoscaled particles of aluminum with the ethanol and $n$ decane-based fuels in the chamber with quartz windows, the rate of agglomeration of the nanoparticles is less than the micron scale agglomeration rate. The nanoparticles burning will continue up to fifth stage, while the process for the microparticles will stop at the third stage. Moreover, in another research (Gan et al. 2012) on the nano fluid fuels, it was revealed that nanoparticles exhibit two different combustion patterns when treated in the dilute and dense concentrations. By experiments on the $\mathrm{Al}$ (aluminum) nanoparticles and liquid fuel using an aerosol rapid compression machine, a reduction of $32-50 \%$ in the ignition delay process was noticed (Allen et al. 2011). The effects of the $\mathrm{Al}$ nanoparticles and $\mathrm{Al}_{2} \mathrm{O}_{3}$ on the heat release rate of the bioethanol fuel were studied (Li 2011), where a linear increase in the heat release was observed with the $\mathrm{Al}$ and decrementation of $\mathrm{Al}_{2} \mathrm{O}_{3}$. Some of the core and shell combinations of the nanoparticles could be used as a core with high combustion energy and a shell with catalyst property. This method was employed on Boron nanopowder (Van Devener et al. 2009) and a new type of fuel introduced with high energy density and catalyst properties. Few researches were performed practically on the diesel engine in the laboratory in terms of exploring the effect of nanoparticles on the engine per- formance and emissions. However, a research conducted in 2012 indicates a simultaneous reduction in NOx and soot when using a catalyst containing nanoparticles (Wang et al. 2012). More recently, with adding an organic nanoparticle to the fuel, a reduction of $30.6 \%$ of NOx and an increase of $14.2 \%$ of the brake thermal efficiency (BTE) were reported (Yang et al. 2013). In a research performed on a diesel engine by applying aluminum nanoparticles (Kao et al. 2008), the smoke rate was reduced in revolutions of $1,200,1,800$, and $2,400 \mathrm{rpm}$, while NOx and BSFC (brake specific fuel consumption) increment was reported in revolutions less than $1,800 \mathrm{rpm}$. Also, experiments on the performance and the emissions of the diesel engines using a mixture of the diesel fuel and carbon nanotubes revealed a new trend of an increase in the BTE along with the reduction in NOx, CO, and HC (Basha and Anand 2010). An investigation carried out in 2009 (Selvan et al. 2009) represents that smoke was absorbed by nanoparticles, and the amount of $\mathrm{CO}, \mathrm{HC}, \mathrm{SFC}$ (specific fuel consumption), and heat release rate was decreased in pressures more than 0.4 MPa when cerium nanoparticles on the diesel fuel were employed on a four-stroke single-cylinder diesel engine. They also reported a reduction in the $\mathrm{HC}$ and the heat release rate and an increase in the BTE in pressures higher than $0.2 \mathrm{MPa}$ when nanoparticles were employed in the mixture of diesel-biodiesel-ethanol. In another test (Sajith et al. 2010) implemented on the Jatrofa biodiesel, a $30 \%$ reduction in NOx, 25-40\% reduction in $\mathrm{HC}$, together with $1.5 \%$ increase in efficiency were acquired. A study in 2011 (Basha and Anand 2011), by making emulsion of water-diesel with alumin, registers a reduction of 11-25 ppm for HC, 300-395 ppm for NOx, a reduction in the heat release rate, and a reduction in the smoke opacity percentage as much as $20-35 \%$ along with $28.8 \%$ increase in efficiency. By implementation of the experiments on $\mathrm{CO}$ emission, a $6 \%$ reduction in $\mathrm{CO}$ concentration has been witnessed during tests with $\mathrm{Al}_{2} \mathrm{O}_{3}$ nanoparticles (Solero 2012).

In order to have a global outlook over physical and chemical properties of nanoparticle combustion with reference to the past experimental works, it was noticed that adopting metal powder as an additive has been long considered as a novel methodology by many researchers (William 1997). However, since a restricted number of investigations (both qualitatively and quantitatively) were performed in this area, also to survey the impact of new metals as nanoparticles on diesel engine, authors are motivated to undertake the current study. In this regard, the effect of silver nanoparticles on the diesel fuel has been investigated in this paper. This research was conducted at nanotechnology laboratories of Tehran and Urmia Uni- 
versities and also at Bioenergy Research Center of Tarbiat Modarres University in May 2013.

\section{Materials and methods}

To prepare the fuel and nanoparticle combination, first the silver powder which was made in the US Nano American company was selected in the range of 30-50 nm dimensions. Also, the sorbitan monooleate surfactant made by Sigma-Aldrich was used for the stability of nanoparticles in the diesel fuel. After only $2 \%$ per volume of the surfactant was solved in the diesel fuel by the homogenizer, silver nanoparticles were added and afterward the prepared mixture was placed for $10 \mathrm{~min}$ in the ultrasonic UP400 s that was constructed by Germany's Heilscher company. Three types of fuel combinations were prepared for the experiment. Firstly, a mixture of the fuel and $10 \mathrm{ppm}$ nanoparticle was made and then in the same manner a mixture of fuel and $20 \mathrm{ppm}$ nanoparticle was obtained and finally a mixture of fuel and $40 \mathrm{ppm}$ nanoparticle was prepared. Three types of fuel mixture in the above-mentioned procedure were denoted by D10, D20, and $\mathrm{D} 40$ in the diagrams accordingly. The type of engine in this experiment is a compression ignition engine with the given features in Table 1. The FTO flow meter made by an American Flowtech company was employed to measure the fuel flow with measurement range between 37 and 1,514 milliliter per minute. Flow meter operates based on a turbine with the magnetic sensor method. To conduct the experiments and control the speed and load, the Sigma 5 dynamometer (made by the English NJFroment company) was used. The given power in the graph is written based on the dynamometer printout. The standard power take off (PTO) speed with 6-gear shaft is $540 \mathrm{rpm}$ in the engine speed of 1,893 and with 21-gear shaft is $1,000 \mathrm{rpm}$ in 1,900 engine speed. In other words, the engine RPM to PTO shaft ratio by 6-gear shaft is 3.51:1 and by 21-gear shaft is 1.9:1. Concerning the MF399 engine, a 21-gear and 1,000 rpm mode has priority due to its empowerment shaft specification; therefore, the 21-gear interface shaft was chosen.

Emission analyzer (made in Germany), which was used in this experiment, is capable of measuring the amount of outflow pollutants such as $\mathrm{O}_{2}, \mathrm{HC}$, $\mathrm{NOx}, \mathrm{CO}, \mathrm{CO}_{2}$ exhaust products components from the exhaust and represents the oil temperature.

Tests were implemented in seven modes by the dynamometer (Table 2), and to ensure the results and its repeatability, the tests were repeated twice. Figure 1 is a schematic picture of experimental set-up. The degree of the machine's precision in measurement has been expressed in Table 3.
Table 1 Properties of engine MF399

\begin{tabular}{ll}
\hline Model & A63544 \\
\hline Company & Motorsazan-Iran \\
Number of cylinders & 6 \\
Bore & $98.6 \mathrm{~mm}$ \\
Stroke & $127 \mathrm{~mm}$ \\
Cubic capacity & 5.81 \\
Max power at 2,300 RPM & $82 \mathrm{~kW}(110 \mathrm{HP})$ \\
Max torque 1,300 RPM & $376 \mathrm{Nm}$ \\
Combustion sequence & $1,5,3,6,2,4$ \\
Combustion system & Direct injection \\
Cooling system & Air cooled \\
Compression ratio & $16: 1$ \\
Injection time & 22 BTDC \\
\hline
\end{tabular}

\section{Results and discussion}

As seen in Fig. 2, the fuel consumption has the highest reduction when 10 and $20 \mathrm{ppm}$ of nanoparticles were added to the fuel. Results of comparing different combinations between modes showed that the maximum fuel consumption for all fuels occurs at the sixth mode and the lowest fuel consumption occurs at the seventh mode. The maximum fuel consumption of $385(\mathrm{ml} / \mathrm{min})$ corresponds to diesel and nanosilver blend with a ratio of $40 \mathrm{ppm}$ in mode 6 , and minimum fuel consumption of $116(\mathrm{ml} / \mathrm{min})$ is related to diesel and nanosilver blend with a ratio of $10 \mathrm{ppm}$ in mode 7. In terms of decreasing trend of the fuel consumption rate for diesel fuel, a decrease of approximately 1-2\% was achieved in most of the compounds. According to Fig. 2, the fuel consumption was decreased by increasing the amount of nanoparticles up to $20 \mathrm{ppm}$. Better fuel distribution in the combustion chamber, shortening of the ignition delay, and promoting the fuel's physical characteristics are among factors which lead to the reduction in the fuel consumption as a result of nanoparticles addition. As deduced by Fig. 2, the fuel consumption trend shows a slight reduction from base diesel to DAG10 that can be explained by the reduction in cohesion force between diesel fuel molecules by introducing nanoparticles resulting in lower fuel injection from the injector via viscosity decrement for the fuel. In contradiction, increasing the nanoparticle concentration (10-40 ppm) yields formation of denser droplets and ligaments through stronger adhesion bonds between fuel molecules and nanoparticles that is conducive to issuing more fuel from injector's nozzle tip. Nanoparticles inclusion in diesel fuel can enhance the momentum of fuel jet injection and the fuel penetration rate in the cylinder, which ultimately produces more uniform air/fuel mixture distribution in the combustion chamber. This outcome is in agreement with similar 


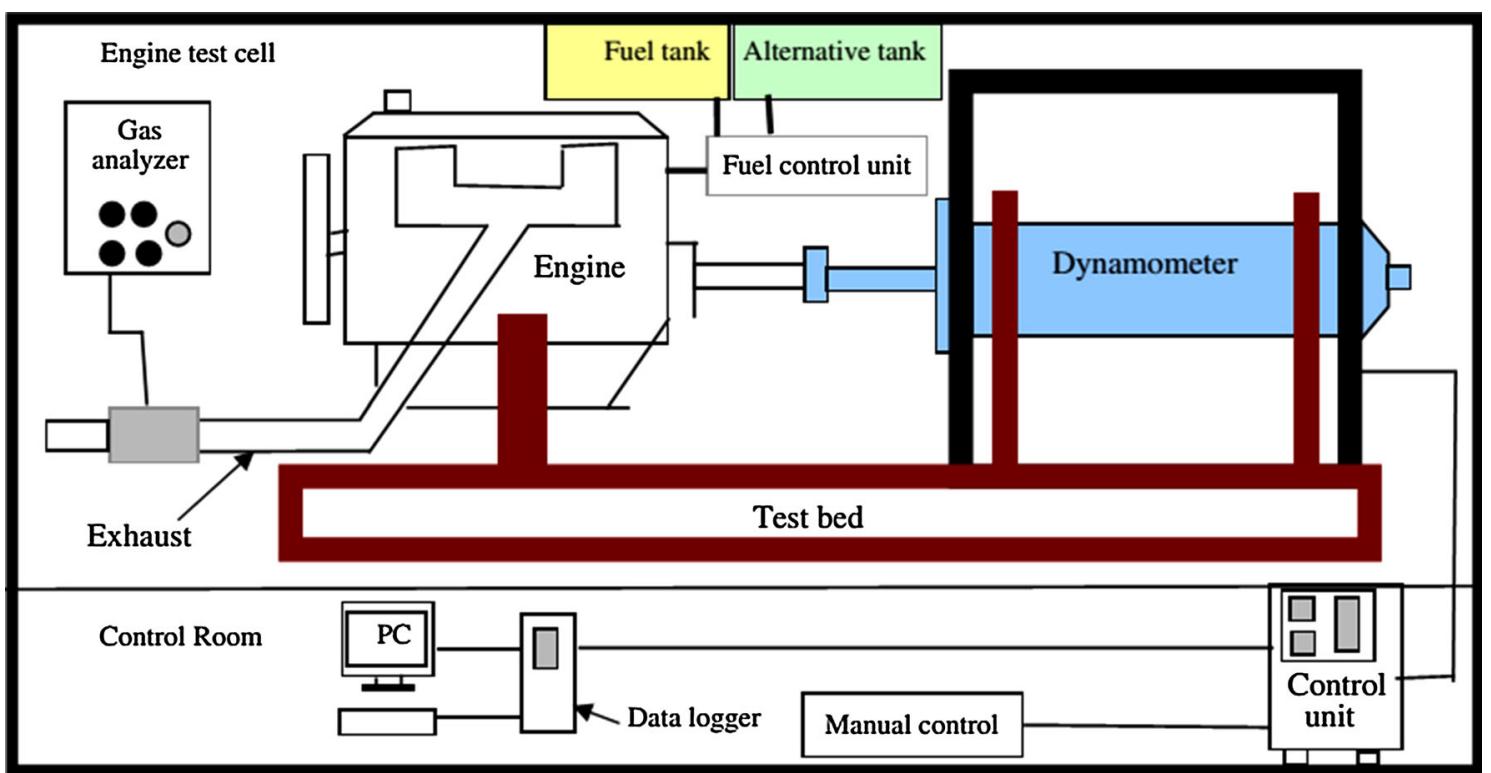

Fig. 1 Schematic picture of experimental set-up

Table 2 Engine test modes

\begin{tabular}{ll}
\hline Mode & Engine speed (RPM) \\
\hline 1 & 1,330 \\
2 & 1,425 \\
3 & 1,520 \\
4 & 1,615 \\
5 & 1,710 \\
6 & 1,805 \\
7 (idel) & 1,900 \\
\hline
\end{tabular}

investigations reporting better charge characteristics while nanoparticles were involved (Yang et al. 2013; Kao et al. 2008; Selvan et al. 2009).

The reason of the increased fuel consumption at $40 \mathrm{ppm}$ mode can be attributed to the increase in viscosity and thereafter an increase in the droplets diameter during the fuel spraying. The maximum reduction rate of $3 \%$ was associated to D10 fuel, and the maximum increase rates of 4.3 and $1 \%$ were associated with D40 fuel in mode 7 and D40 fuel in mode 6 , respectively. Indicated values by dynamometer in modes 3 and 5 suggest the highest values in terms of the engine torque and power. Regarding the specific fuel consumption, the mentioned cases prevail from economical standpoint when tests run in these modes.

As seen in Fig. 3, the $\mathrm{CO}$ emission in relation to the base fuel mode has a perceptible reduction with respect to enhanced mixture by nanoparticles. This outcome is in accordance with similar investigations taking nanoparticles in fuel composition (Basha and Anand 2010; Selvan et al. 2009; Solero 2012). The nanoparticle free fuel has

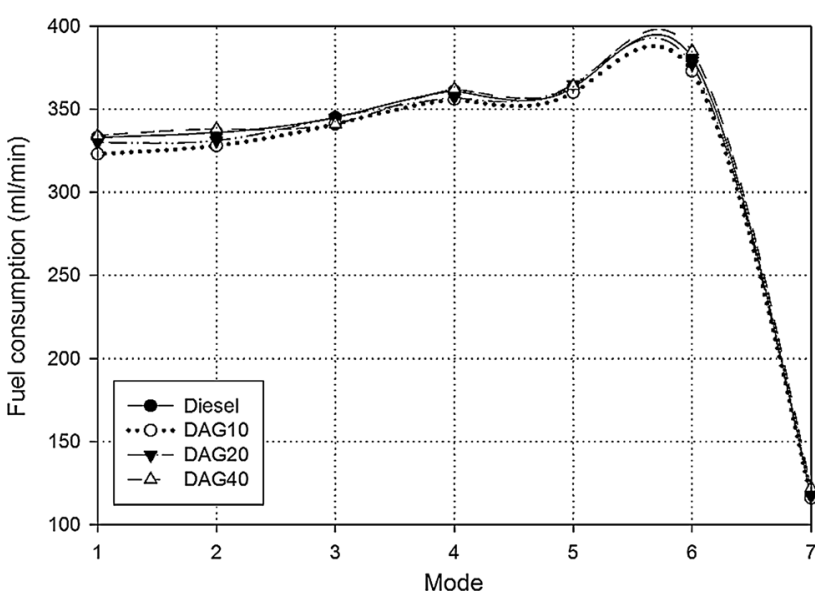

Fig. 2 Variation of FC with respect to speed modes

substantially higher $\mathrm{CO}$ emission, which is attributed to the cohesion inter-molecular bonds of diesel. Increasing the nanoparticle percentage involvement decreases the homogeneity of base fuel composition, thus expediting fuel disintegration and breakup during fuel injection. More fuel breakup causes better air-fuel mixture and reduction in equivalence ratio, which ultimately can decrease the $\mathrm{CO}$ emitted with DAG40 fueled engine.

In most cases, the approximate 20.48 and $40-70 \%$ fuel consumption reduction was obtained compared to that of the base diesel fuel for D40, respectively, in loading conditions of dynamometer and idle mode (mode 7).

In the high loads of the dynamometer, the engine reaches to the smoke limit, hence the $\mathrm{CO}$ and $\mathrm{UHC}$ (unburned hydrocarbons) emissions increase in all of the 
Table 3 Measurement precision

\begin{tabular}{ll}
\hline Parameters & Accuracy \\
\hline Engine speed & $\pm 1 \mathrm{rpm}$ \\
Engine torque & $\pm 1 \mathrm{Nm}$ \\
NOx emissions & $\pm 5 \%$ \\
$\mathrm{CO}$ emissions & $\pm 1 \%$ \\
$\mathrm{CO}_{2}$ emissions & $\pm 2 \%$ \\
$\mathrm{HC}$ emissions & $\pm 2 \%$ \\
Fuel flow rate measurement & $\pm 1 \%$ \\
Lower heating value of the fuel & $\pm 4 \%$
\end{tabular}

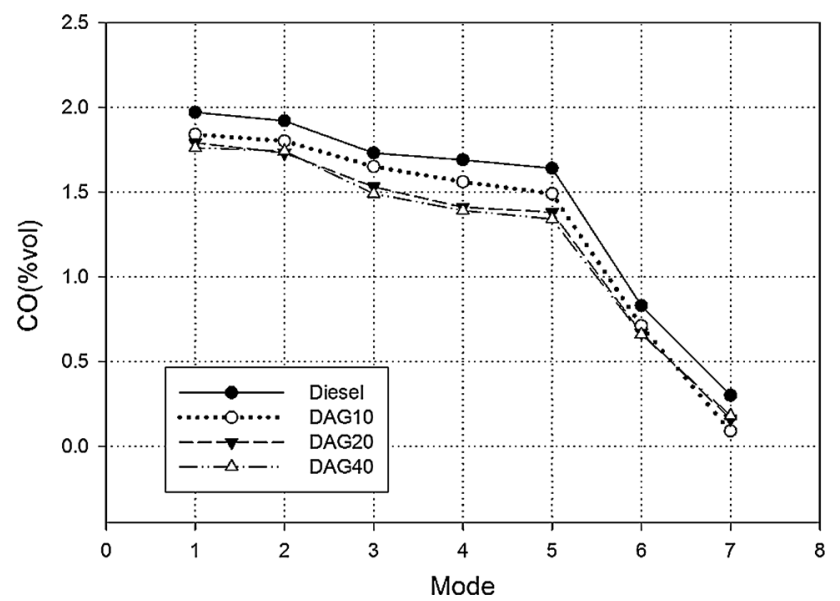

Fig. 3 Variation of $\mathrm{CO}$ with respect to various modes

fuels. This is due to the oxygen shortage for the engine's operation in the air/fuel ratio higher than unity (stoichiometric). The rate of changes after D20 is very low and adding more nanoparticles has no significant effect.

As seen in Fig. 4, silver nanoparticles have declining effect on NOx and it keeps decreasing up to $13 \%$ for D40 in loading conditions of dynamometer and 20-23\% in idle mode (mode 7). Maximum NOx of 1,427 ppm is related to diesel fuel in mode 1, and minimum NOx of $250 \mathrm{ppm}$ is related to the composition of the diesel and nanosilver with a ratio of $20 \mathrm{ppm}$ in mode 7 .

Numerous factors give rise to the particular formation of NOx emissions. According to the Zeldovich mechanism, the formation of NOx is dependent on oxygen concentration, residence time, and temperature (Benson and Whitehouse 1983). The temperature decline in the combustion chamber as a result of adding nanoparticles accounts for the NOx reduction. This outcome is in agreement with similar investigations that were carried out for nanoparticles (Yang et al. 2013; Kao et al. 2008; Basha and Anand 2010; Selvan et al. 2009; Sajith et al. 2010; Basha and Anand 2011). As known, the nanoparticles feature

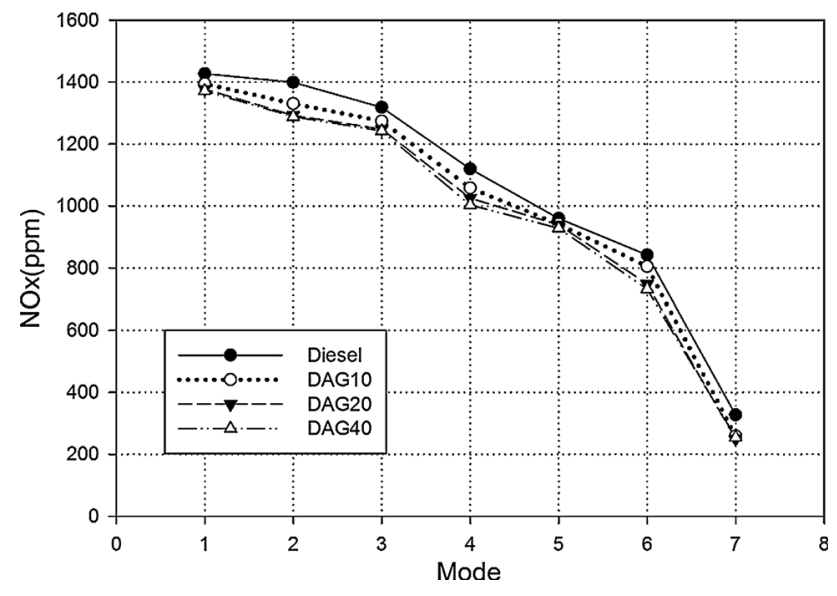

Fig. 4 Variation of NOx with respect to various modes

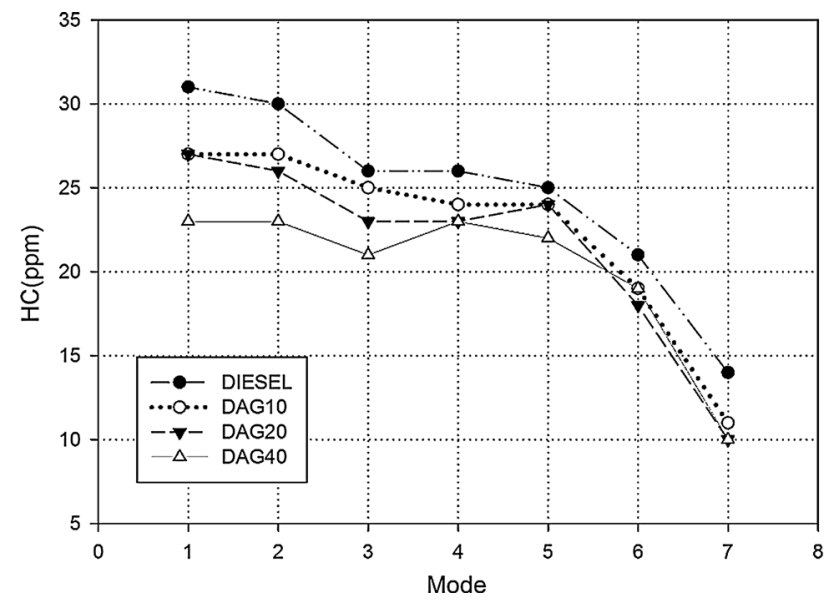

Fig. 5 Variation of $\mathrm{HC}$ with respect to various modes

exceptional capability of heat transfer. One of the pivotal advantages of nanoparticle addition is its potential in decreasing the combustion chamber temperature with high rate of convective heat transfer increasing nano fraction in fuel leads to lowering the NOx emission.

UHC is considered as an emission that actively affects the engine efficiency unfavorably. Unburned or incomplete burned hydrocarbons were generated as a result of insufficient air accessible during fuel combustion. HC emission has been affected the most by application of metallic nanoparticles. According to Fig. 5, HC emission has a range of 4-28\% reduction and with the increment of silver amount will be reduced for all fuels with respect to the base fuel. This result can be corroborated with the reported studies of Yang et al. 2013, Kao et al. 2008, Basha and Anand 2010, Selvan et al. 2009, Sajith et al. 2010, and Basha and Anand 2011. However, due to the low content of $\mathrm{HC}$ in the operated diesel engine, the reduction in $\mathrm{HC}$ is of minor importance. The higher percentage of incomplete 
combustion in the combustion chamber leads to the generation of UHC especially at higher equivalence ratio and hence a considerable efficiency decrement. As mentioned, nanoparticle involvement enhances the air-fuel mixing process and lower equivalence ratio, which brings about complete combustion, therefore higher thermal efficiency. The more nanoadditive, the more fuel spray droplet interaction and fuel droplet propagation.

The addition of silver nanoparticles to the fuel can widen the spray cone angle and facilitate the injected fuel's dispersion in the combustion chamber. The metallic particle existence in the pure liquid fuel with different density and momentum in the injection period along with their interaction accounts for better spray dispersion. On the other hand, establishment of a more complete combustion due to the more oxygen availability and silver properties would decrease these pollutants that were illustrated in Figs. 5, 6, 7. As indicated in former discussions, applying nanoparticles incurs reduction in fuel cohesion resulting in easier fuel breakup and creating smaller droplets or lower Sauter mean diameter, hence exposing more fuel surface to $\mathrm{O}_{2}$ oxidizer and thereby higher $\mathrm{CO}_{2}$ production.

$\mathrm{CO}_{2}$ emissions are depicted as a function of various dynamometer loads for different fuel blends of nanoparticle portions in Fig. 6. As seen, $\mathrm{CO}_{2}$ emission resulted from nanoparticle-containing fuels is higher than that of pure diesel fuel at different dynamometer loads.

For the more oxygen availability and catalytic activities, existence of a fraction of nanoparticles improves spray quality and combustion phase which will increase $\mathrm{CO}_{2}$ emission concentration and thus decreases the emissions amount of $\mathrm{CO}$ and UHC incomplete combustion products.

Metals were often used as reducing catalysts rather than a catalyst for oxidation. But silver is an exception and was also used as an oxidation catalyst (Claus and Hofmeister 1999; Kvitek and Robert 2005; Prucek et al. 2004). Therefore, the application of this metal is suitable for the oxidation of organic compounds and also reducing nitro compounds and many others as well. On the other hand, the high surface area and surface energy will increase the performance of metallic nanoparticles. Any material involving the catalytic activity certainly has a high contact surface area. Because the surface of nanomaterials increases with decreasing the size, these materials are extensively used in catalysis. For example, in a crystal with a diameter of $10 \mathrm{~nm}, 15 \%$ of the atoms are located on the surface, whereas in the nanocrystals with $1 \mathrm{~nm}$ diameter, all of the atoms are placed on the surface area. So a small nanocrystal with high surface will have more catalytic activity (Claus and Hofmeister 1999).

It can be inferred from the charts (with the exception of $\mathrm{HC})$ that variation of emissions for higher nanofraction than D20 is little and it remains almost monotonous.

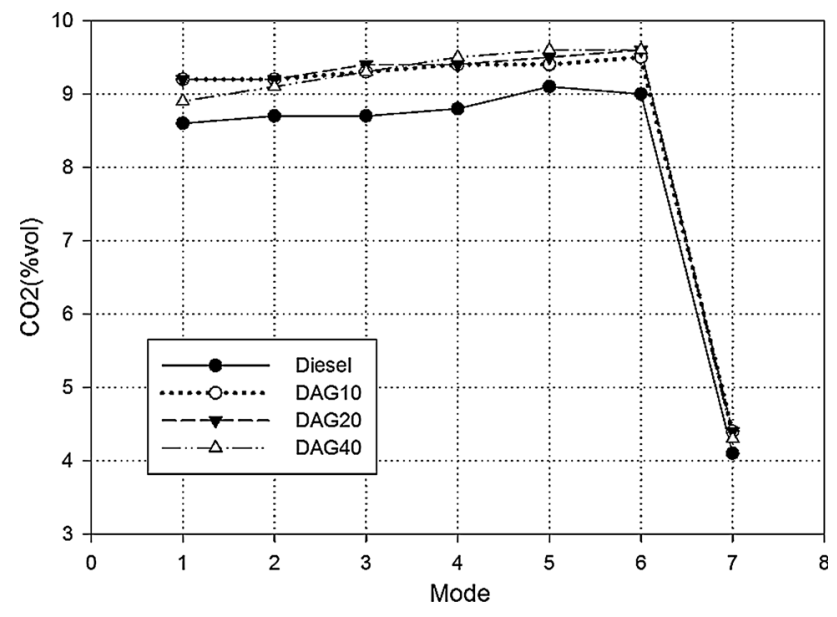

Fig. 6 Variation of $\mathrm{CO}_{2}$ with respect to various modes

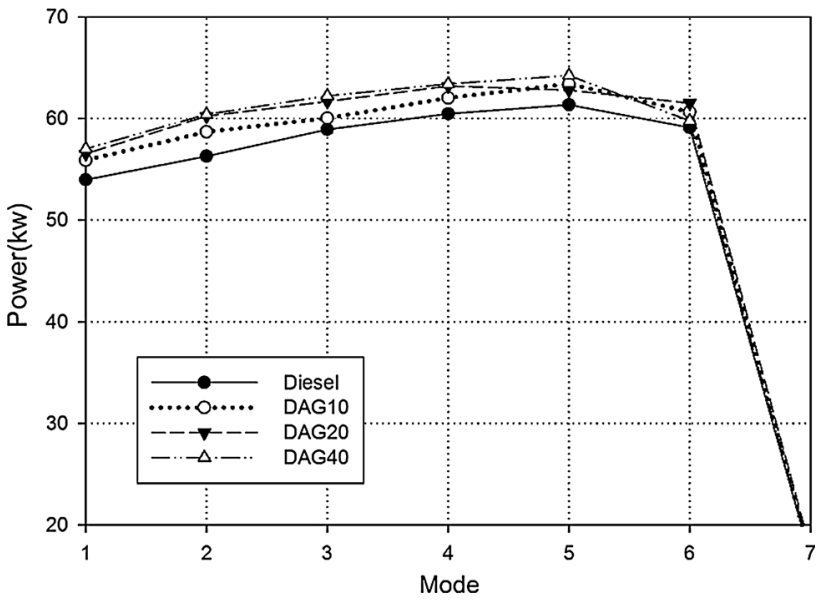

Fig. 7 Variation of Power with respect to various modes

Therefor, adding nanoparticles to diesel fuel was implemented up to $40 \mathrm{ppm}$.

According to Fig. 7, brake power increases with adding nanoparticles in fuel combination which implies fuel combustion improvement and higher rate for fuel energy conversion into useful work.

The engine power has increased in the range of 1.1-7.3\% tolerance compared to the base fuel. This outcome is in agreement with similar investigations using nanoparticles (Yang et al. 2013; Kao et al. 2008; Basha and Anand 2010; Selvan et al. 2009; Sajith et al. 2010; Basha and Anand 2011).

Results of comparing combinations between modes showed that the maximum power for all fuels occurred in the fifth mode and the lowest power occurred in the seventh mode. The maximum power of $64.2 \mathrm{~kW}$ is associated with diesel and nanosilver blend with a ratio of $40 \mathrm{ppm}$ in mode 5 and minimum power of $16.7 \mathrm{~kW}$ is associated with net diesel in mode 7 . In terms of power increase rate of diesel 
fuel, a growth of approximately $4 \%$ was achieved in most of the compounds. According to Fig. 7, the power has been increased by increasing the amount of nanoparticles, but this growth rate has been decreased after adding $20 \mathrm{ppm}$ of nanoparticles and it was demonstrated that the addition of nanoparticles over this threshold has no significant impact on power. Maximum growth rates of 7.3 and $7 \%$ for D40 and D20 fuels were achieved in mode 2 , respectively. The minimum growth rates of 1.1 and $1.3 \%$ were associated with D40 fuel in mode 6 and D10 fuel in mode 7 , respectively.

Because of the above-mentioned reasons and the existence of metallic particles inside the chamber, better air/ fuel mixture is expected, and additionally because of the catalytic role of the silver, the higher rate of energy release is certified. This increase could be due to the increased energy produced in the cylinder as increasing the surface to volume ratio of nanoparticles and increasing the heat transfer coefficient with nanoparticles in the fuel.

\section{Conclusion}

Based on the obtained results from the experiments and diagrams, it was observed that adding silver nanoparticles to the diesel fuel will improve the fuel consumption and the extent of emitted pollution. Adding the metallic particles will increase the fuel infiltration and mixing with air, that this improves the combustion process. Also, these metallic particles will accelerate the fuel evaporation and will reduce the ignition delay in the combustion process.

Acknowledgments Authors would like to thank the nanotechnology laboratories of Tehran and Urmia Universities and also Bioenergy Research Center of Tarbiat Modarres University for their help in conducting the experiments. Our sincere gratitude toward Prof. Farhadi and Dr. Ghobadian for their support related to the Nanotechnology and engine test sections of this paper. This work is financially supported by the Iran Nanotechnology Initiative Council (Grant Number 46680). In the end, the authors are thankful to the editor and the reviewers for their constructive comments.

\section{References}

Allen C, Mittal G, Sung C, Toulson E, Lee T (2011) An aerosol rapid compression machine for studying energetic-nanoparticleenhanced combustion of liquid fuels. Proc Combust Inst 33(2):3367-3374

Basha JS, Anand R (2010) Performance and emission characteristics of a DI compression ignition engine using carbon nanotubes blended diesel. Int J Adv Ther Sci Eng 1:67-76

Basha JS, Anand R (2011) An experimental study in a CI engine using nanoadditive blended water-diesel emulsion fuel. Int $\mathrm{J}$ Green Energy 8(3):332-348

Benson R, Whitehouse ND (1983) Internal combustion engines. Pergamon press, Oxford
Bertola A, Li R, Boulouchos K (2003) Influence of water-diesel fuel emulsions and EGR on combustion and exhaust emissions of heavy duty DI-diesel engines equipped with common-rail injection system. SAE Trans 112(4):2244-2260

Claus P, Hofmeister H (1999) Electron microscopy and catalytic study of silver catalysts: structure sensitivity of the hydrogenation of crotonaldehyde. J Phys Chem B 103(14):2766-2775

De Luca L, Galfetti L, Severini F, Meda L, Marra G, Vorozhtsov A, Sedoi V, Babuk V (2005) Burning of nano-aluminized composite rocket propellants. Combust Explos Shock Waves 41(6):680-692

Evans B, Favorito NA, Boyer E, Risha GA, Wehrman RB, Kuo KK (2004) Characterization of nano-sized energetic particle enhancement of solid-fuel burning rates in an X-ray transparent hybrid rocket engine. AIAA Paper 3821:40

Galfetti L, Deluca L, Severini F, Colombo G, Meda L, Marra G (2007) Pre and post-burning analysis of nano-aluminized solid rocket propellants. Aerosp Sci Technol 11(1):26-32

Gan Y, Qiao L (2011) Combustion characteristics of fuel droplets with addition of nano and micron-sized aluminum particles. Combust Flame 158(2):354-368

Gan Y, Lim YS, Qiao L (2012) Combustion of nanofluid fuels with the addition of boron and iron particles at dilute and dense concentrations. Combust Flame 159(4):1732-1740

Harbach J, Agosta V (1991) Effects of emulsified fuel on combustion in a four-stroke diesel engine 35(4):356-367

Ivanov GV, Tepper F (1997) 'Activated' aluminum as a stored energy source for propellants. Int $\mathbf{J}$ Energ Mater Chem Propuls 4:1-6

Jung H, Kittelson DB, Zachariah MR (2005) The influence of a cerium additive on ultrafine diesel particle emissions and kinetics of oxidation. Combust Flame 142(3):276-288

Kao M, Ting C, Lin B, Tsung T (2008) Aqueous aluminum nanofluid combustion in diesel fuel. J Test Eval 36(2):503

Kuo KK, Risha GA, Evans BJ, Boyer E (2004) Potential usage of energetic nano-sized powders for combustion and rocket propulsion. 800:3-14

Kvitek L, Robert P (2005) The preparation and application of silver nanoparticles. J Mater Sci 22:2461-2473

Li CH (2011) Experimental study of nanoadditives for biofuel combustion improvement. pp 1727-1734

Pivkina A, Ulyanova P, Frolov Y, Zavyalov S, Schoonman J (2004) Nanomaterials for heterogeneous combustion. Propellants Explos Pyrotech 29(1):39-48

Prucek R, Kv'itek L, Hrb'avc J (2004) Silver colloids-methods of preparation and utilization. Chemica 43:59

Sajith V, Sobhan C, Peterson G (2010) Experimental investigations on the effects of cerium oxide nanoparticle fuel additives on biodiesel. Adv Mech Eng 2010:6. doi:10.1155/2010/581407

Satge De Caro P, Mouloungui Z, Vaitilingom G, Berge JC (2001) Interest of combining an additive with diesel-ethanol blends for use in diesel engines. Fuel 80(4):565-574

Selvan V, Anand RB, Udayakumar M (2009) Effects of cerium oxide nanoparticle addition in diesel and diesel-biodiesel-ethanol blends on the performance and emission characteristics of a $\mathrm{CI}$ engine. J Eng Appl Sci 4(7):1819-6608

Solero G (2012) Experimental analysis of the influence of inert nanoadditives upon combustion of diesel sprays. Nanosci Nanotechnol 2(4):129-133

Tyagi H, Phelan PE, Prasher R, Peck R, Lee T, Pacheco JR, Arentzen $P$ (2008) Increased hot-plate ignition probability for nanoparticle-laden diesel fuel. Nano Lett 8(5):1410-1416

Van Devener B, Perez JPL, Jankovich J, Anderson SL (2009) Oxidefree, catalyst-coated, fuel-soluble, air-stable boron nanopowder as combined combustion catalyst and high energy density fuel. Energy Fuels 23(12):6111-6120 
Wang H, Xu C, Wei Y, Zhao Z, Liu J (2012) Comparative study of nanometric Co-, $\mathrm{Mn}$ - and Fe-based Provskite-type complex oxide catalysts for the simultaneous elimination soot and NOx from diesel engine exhaust. Catal Today 184:288-300

Williams F (1997) Some aspects of metal particle combustion. Physical and chemical aspects of combustion: a tribute to Irvin Glassman. Gordon and Breach, Netherlands, p 267

Xiaolu L, Hongyan C, Zhiyong Z, Zhen H (2006) Study of combustion and emission characteristics of a diesel engine operated with dimethyl carbonate. Energy Convers Manag 47(11):1438-1448

Yang W, An H, Chou S, Vedharaji S, Vallinagam R, Balaji M, Mohammad F, Chua K (2013) Emulsion fuel with novel nanoorganic additives for diesel engine application. Fuel 104:726-731

Yetter RA, Risha GA, Son SF (2009) Metal particle combustion and nanotechnology. Proc Combust Inst 32(2):1819-1838 